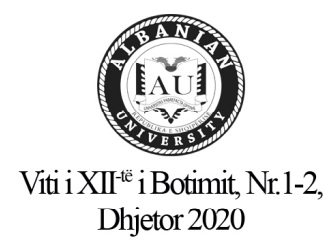

\title{
ANEURIZMA GJIGANDE E AORTËS ASCENDENTE TORAKALE
}

\author{
A. Kaçani*, A.Aliu* , S.Kuçi ,E.Mıle***, A.Veseli*,A Dibra**,E Prifti*
}

*Klinika e kardiokirurgjisë, QSUT

**Klinika kardiologjisë, QSUT

$* * *$ Klinika kardiologjisë, SBLu

Adresë kontakti: akacani@yahoo.com

\section{Përmbledhje}

Aneurizmat gjigande e Aortës Ascendente (AAA) bashkëshoqëruar me zgjerim shumë të madh të rrënjës së aortës, janë të raportuar shumë rrallë. Ne do paraqesim rastin e një AAA gjigande tek një pacient 68 vjeçar i cili iu nënshtua një interventi kirurgjikal të suksesshëm të zëvendësimit të aortës ascendente dhe rrënjës së saj duke përdorur teknikën e modifikuar të Bentall nëpërmjet një konduiti të kompozuar me valvë mekanike dhe shoqëruar me implantim të arterieve koronare.

Fjalë çelës; Aneurizma e Aortes Ascendente, teknika Bentall

\section{GIANT ASCENDING THORACAL AORTA ANEURYSM}

\begin{abstract}
Giant ascending aorta aneurysms (AAA) with greatly enlarged aortic root, are rarely been reported. We present the case of a Giant AAA of about 8,7 cm diameter in a 68 -yearold man who was successfully operated on for ascending aorta and aortic root replacement under modified Bentall technique using composite mechanical conduit with coronary reimplantation.
\end{abstract}

Keywords: Ascending Aaorta Aneurysm, Bentall technique 
ANEURIZMA GJIGANDE E AORTËS ASCENDENTE TORAKALE

\section{Hyrje}

Rrallë ndodh të prezantohemi me aneurizëm gjigande të aortës ascendente, për arsye të rritjes së incidencës së diagnostikimit në stade të hershëm si rezultat i kontrollove mjekësore rutine, rritjes së ndërgjegjësimit shëndetësor dhe përparimit të teknikave imazherike. Etiologjia e aneurizmës së

aortës bashkëshoqëruar me zgjerim të rrënjës së saj mund të jetë me origjinë gjenetike, degjenerative apo aterosklerotike, inflamatore ose mund të jetë nga sëmundje infektive. Bazuar në shumë studime, për aneurizëm të aortës ascendente më shumë se $6 \mathrm{~cm}$, risku për rupturë, disekim apo vdekje shkon mesatarisht $15.6 \%$ duke e bërë këtë aneurizëm me rrezikshmëri të lartë për jetën.Teknıka e zgjedhur për riparimin e rrënjës dhë aneurizmës së aorte ascendente, në rastet ku ruajtja e valvulës aortë është e pa rekomandueshme ose e pamundur, është teknika Bentall I modifikuar e c1la ka rezultate të shkëlqyera. Në rastin tonë, valvula e aortes ishte insuficiencë e përparuar edhe pse kuspiset aortike ishin normal, kishte humbje të junksionit sinotubular si pasojë e dilatimit gjigant të aortës e cila mund të pasohet me dilatacion të mëtejshëm të rrënjës dhe unazës së aortës dhe me moskoaptim adekuat të fletëve valvulare dhe si rezultat regurgitim aortal rekurent. Në vlerësimin preoperator të ndërhyrjeve të aortës ascendente dhe rrënjës së saj, është me rëndësi vlerësimi me EKO kardiake transezofageale dhe angio-ct për të marë një informacion sa më të plotë për shtrirjen e aneurizmës, në mënyrë që të bëhet një plan operator sa më i saktë sidomos në lidhje me llojın e interventıt. Sıç e dimë janë disa 1loj operacıonesh: zëvendësım vetëm i aortës ascendente me protezë sıntetıke (në këtë rast këto ekzamınıme janë të rëndësıshme për të përcaktuar nıvelın e anastomozava) në rastet kur rrënja e aortës nuk është e dılatuar, ose e shoqëruar me zëvendësım ose rıparım të valvulës së aortës sı dhe me implantım ose jo të ost1umeve koronare. Për pacientë mbi 40 vjeç nevojitet bërja e koronarografisë për të vlerësuar pemën koronare.

\section{Paraqitja e rastit}

Pacienti S.B 68 vjeç u paraqit pranë klinikës tonë pas të dhënave të marra nga angio-Ct $\mathrm{i}$ bërë në shërbimin e urgjencës. Pa historik të mëparshëm mjekësor, referonte vetëm një periudhë 3 mujore me dispne progresive, sidomos dy javët e fundit shoqëruar me diskomfort torakal. Pacienti ka vuajtur nga hipertensioni arterial prej shumë vitesh, trajtuar në mënyrë jotë rregullt dhe një histori të gjatë duhanpirje. Në ekzaminim objektiv përveçse një zhurme diastolike, parametrat hemodinamike ishin stabël. Ekzaminimet laboratorike, hemogramë, biokimike, enzimat kardiake rezultuan në vlera normale. Po ashtu dhe ekzaminimet e sistemeve të tjera. 

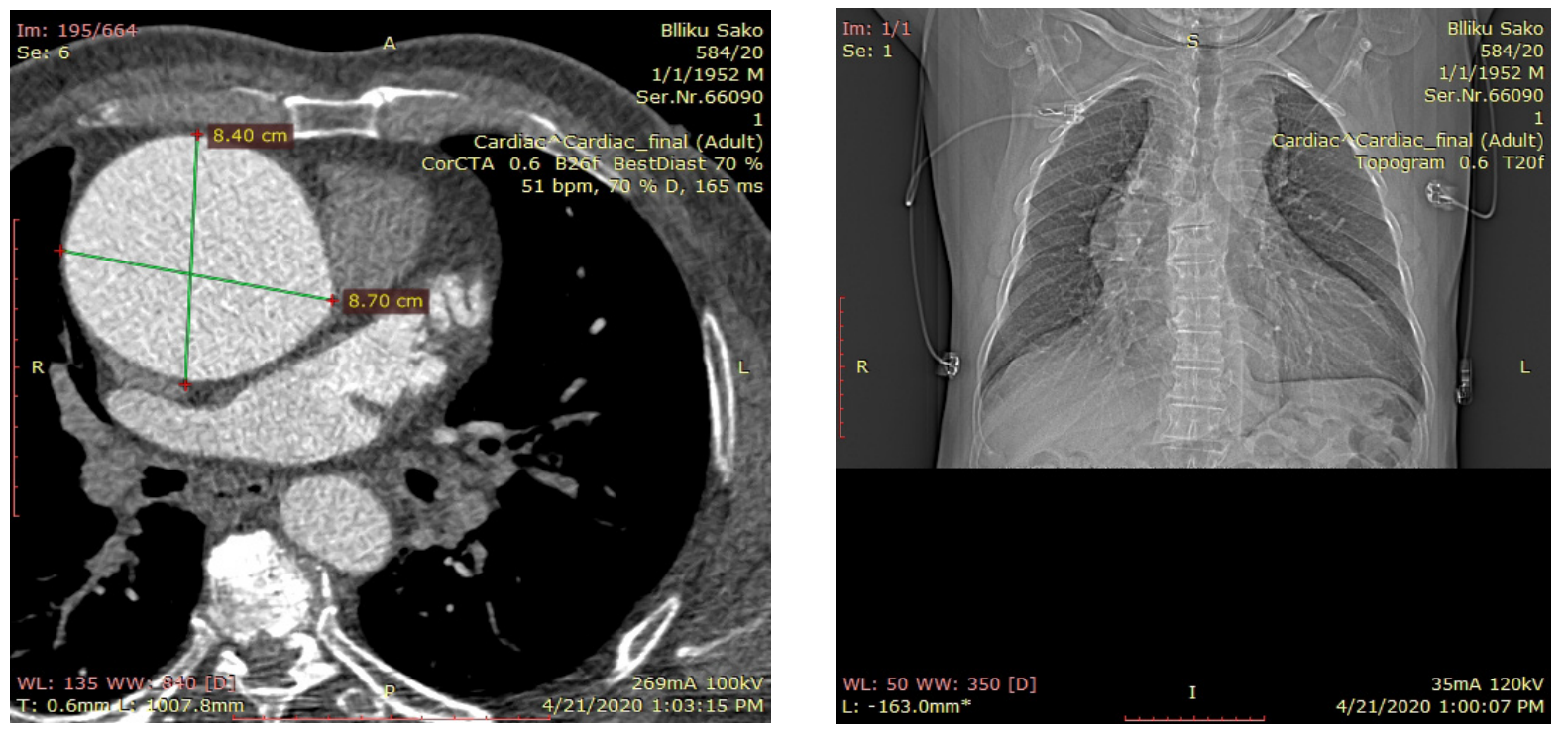

Fig. 1 Imazheria tridimensionale e cila evidentoi aneurizmin e aortës.

Angioskaneri me kontrast rezultoi me aneurizëm aorte gjigande 87 x $84 \mathrm{~mm}$, bulbi i aortës $67 \mathrm{~mm}$, harku aortës $35-44 \mathrm{~mm}$, aorta descendente $28 \mathrm{~mm}$, pa të dhëna për disekim. Koronarografia rezultoi pa stenoza sinjifikative. Në eko kardiake evidentohet ventrikul i majtë hipertrofik, DTD $70 \mathrm{~mm}$, EF 50\%, valvula e aortës trikuspidike me insuficiencë të përparuar, aorta ascendente $87 \mathrm{~mm}$, bulbi aortës 67 , unaza aortës $28 \mathrm{~mm}$, regurgitim të lehtë mitral, PSAP $25 \mathrm{mmHg}$. Echo doppler arteria karotide pa stenoze sinjifikative. ECG RS, SV1-V3, RV4-V6.
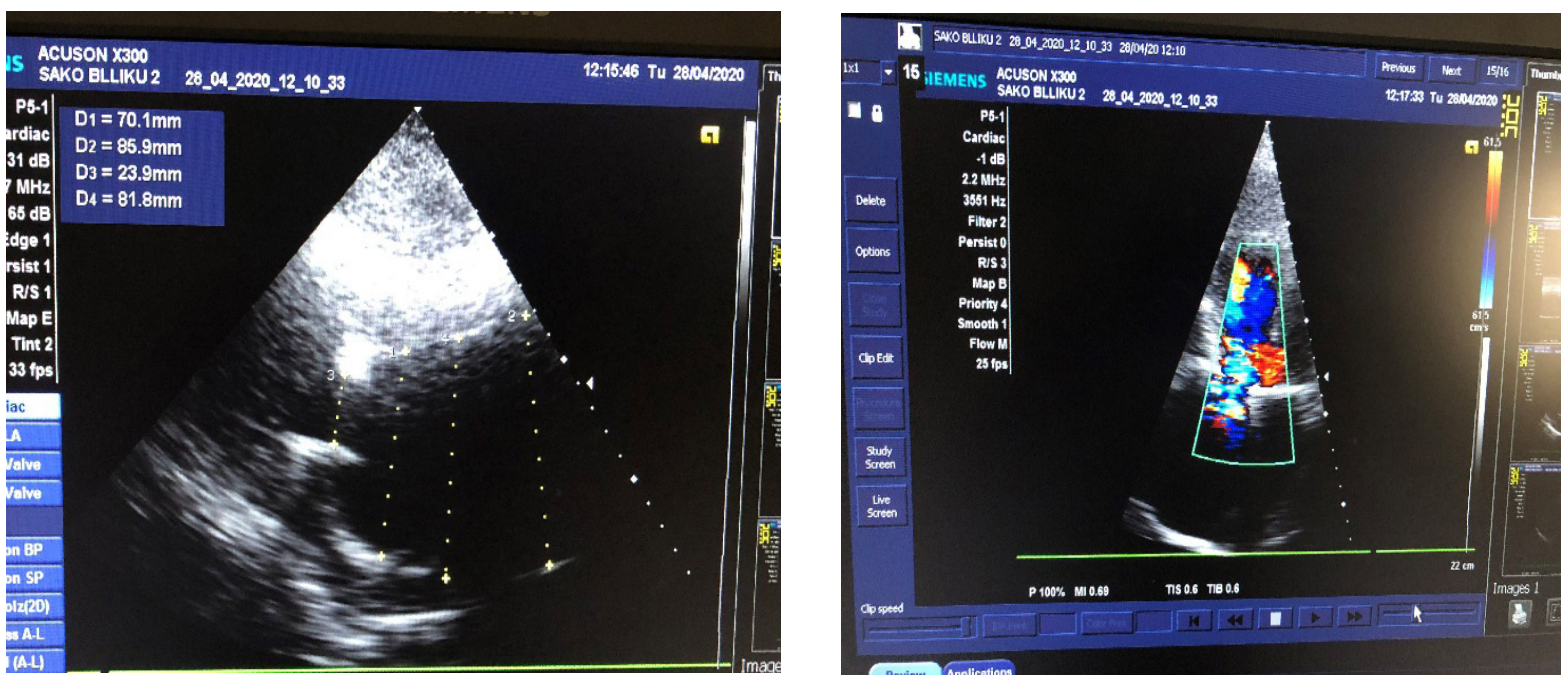

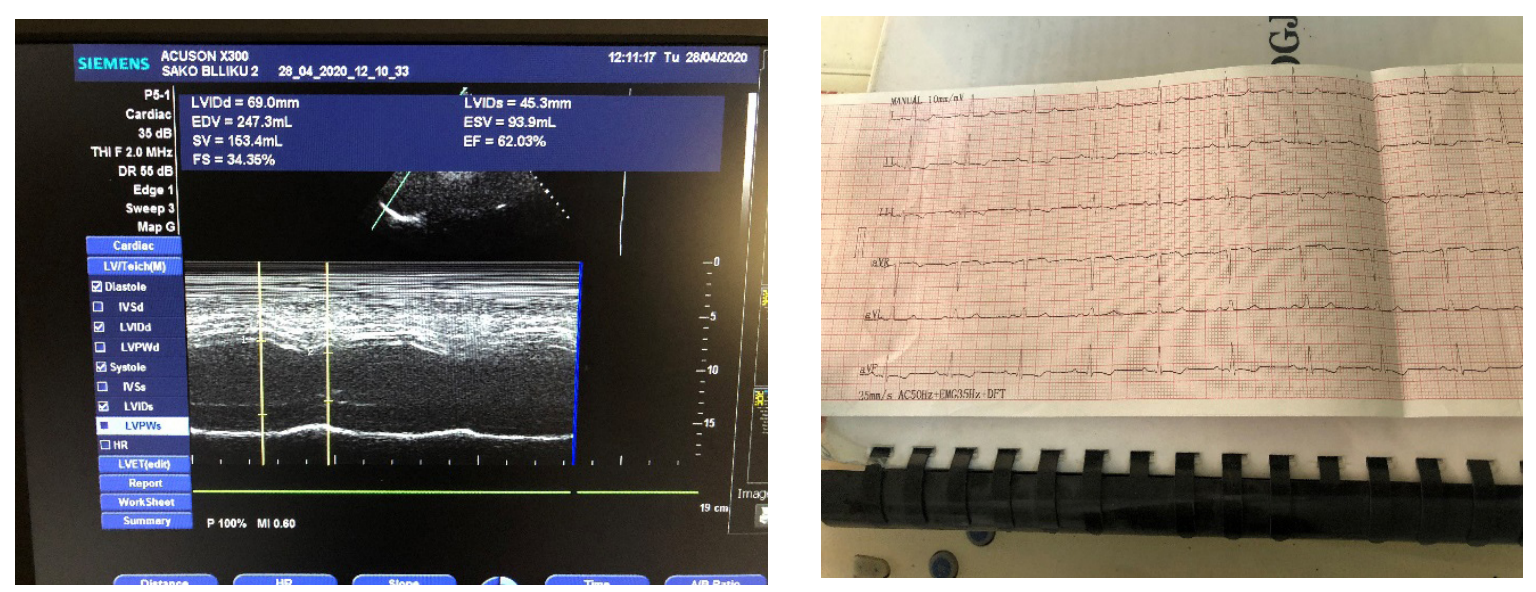

Fig.2 Ekografi kardiake evidentohet ventrikul i majtë hipertrofik

Për arsye të zgjerimit shumë të madh të rrënjës së aortës dhe insuficiencës së aortës së pariparueshme u përzgjodh teknika Bentall i modifikuar me 1mplantım graftı të valvuluar nr 27 SJM dhe implantim të ostiumeve të arterieve koronare.

Interventi u realizua nëpërmjet sternotomisë mediane pas së cilës u evidentua një aorte gjigande u bë kanjulimi aorto monocaval dhe u përdor $800 \mathrm{ml}$ solucion kristaloid si dozë e parë dhe $3 \times 600 \mathrm{ml}$ kardioplegji me gjak normotermik. U rezekua valvula e aortës dhe aorta ascendente nga rrënja deri në origjinën e trungut brachiocefalik në pjesën proksimale të harkut të aortës. Pacienti ju nënshtruar procëdures Bentall të modifikuar me graft të valvuluar SJM nr 27 dhe me reimplantim te koronareve. Koha e qarkullimit ekstrakorporal ishte 165 min, koha e klampazhit 115 min.

Pacıentı patı një dekurs të mırë në perıudhën post operatore.

Prurjet nga dreni torakal ishin $550 \mathrm{ml}$ serohemoragjik. U extubua pas 6 orësh dhe doli nga reanimacioni pas 40 oresh. Echo kardiake post operatore rezultoi me protezë valvulare normofunksionale Gmes $10 \mathrm{mmHg}$ dhe Gmax $16 \mathrm{mmHg}$, Vmax $=2.0 \mathrm{~m} / \mathrm{s}$.

Pacienti doli nga spitali ne gjendje shumë të mirë ditën e 8 post operatore. 
A. Kaçani, A.Aliu, S.Kuçi, E.Mıle, A.Veseli, A Dibra, E Prifti

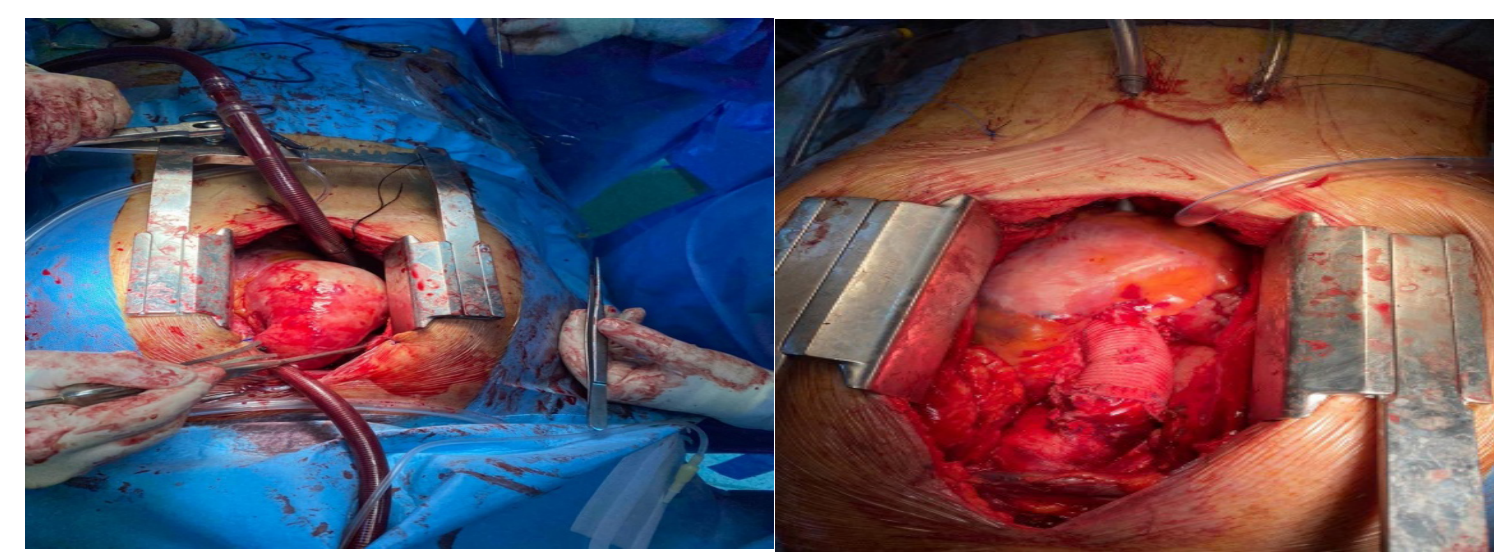

Fig. 3 Foto intraoperatore para dhe pas zëvendësimit Aortës Ascendente, rrënjës dhe valvulës së saj sipas procedurës Bentall modifikuar

\section{Diskutime}

Aneurizmat gjigande mund të paraqitet në mënyra të ndryshme. Mund të paraqitet me komplikimet e saj më të rrezikshme që jane disekimi dhe rupturën e aortës por ka dhe raste të rralla që është asimptomatike.Më së shumti aneurizmat e aortës lokalizohen në pjesën ascenł dente me $60 \%$ të rasteve pasuar me ato të aortës descendente $35 \%$ dhe harkun e aortës 10 \%. Shkaktari patologjik më i shpeshtë është nekroza mediale cistike.

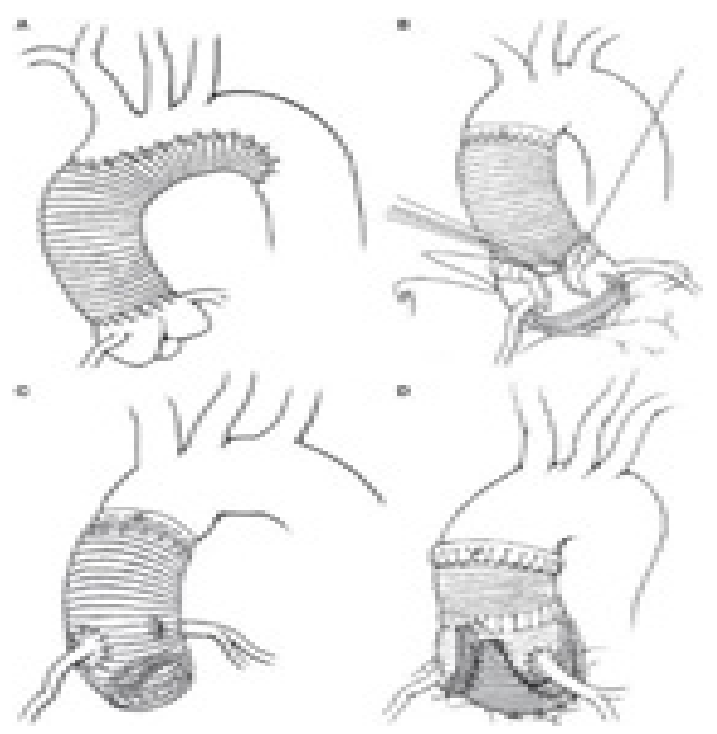

Fig 4; Teknika kirurgjikale të trajtimit të aortës ascendente, dhe kur bashkëshoqërohet me zëvedësim të rrënjës aortës: A- Zëvendësim i aortës ascendete dhe hemiharkut, BZëvendësim i aortës ascendente, C- Procedura Bentall i modifikuar, D- "Valve-Sparing" sipas Yakoob apo David 
Në aneurizmat aortës ascendente dhe për më tepër në ato gjıkande diskutımet, studımet dhe dilemat e kırurgut lidhen me nivelin e realizimit të anastomozave pasi këto përcaktojnë jo vetëm llojin dhe suksesin e interventit por edhe rezultatin afatgjatë dhe nevojën për riintervent.Qëllimi i interventit është të zëvendësojë të gjithë aortën e dilatuar dhe të realizojë anastomoza në ind të shëndoshë që të uli riskun e dilatimit të mëtejshëm ose rupturës në zonat kufitare. Ndaj sic e thame ëdhe më sipër ekzaminimet janë shumë të rëndësishme për të vendosur strategjinë dhe llojin e interventit që do kryejmë.

Në rast se harku i aortës është i dilatuar duhet zëvendësuar edhe kjo pjesë e aortës dhe mund të duhet të bëhet zëvendesim i plotë ose i pjesshëm i harkut të aortës. Për të realizuar këtë ne realizojme teknikën më kontemporane :arrest cikulator me perfuzion selektiv anterograde të trurit me hypotermi të moderuar (temp. 28 gradë Celsius). Kjo teknikë në ndryshim nga teknika me hypotermi të thellë mbart më pak risk për komplikacione neurologjike dhe hemoragji. Në dekadën e fundit rezultatet e raportuara për teknikën me hipotermi të moderuar janë shumë kurajuese, evente neurologjike më pak se 2\% në rastet elektive. Gjithsesi në rastin tonë siç shikohet edhe nga ekzaminimet e kryera nuk ishte e nevojshme zëvendësimi i harku të aortës dhe bërja e arrestit cirkulator gjë që minimizon rrezikun e eventeve neurologjike.

Në rastet e planifikuara mortaliteti operator është rreth 1.5-2.0\% të krahasueshëm edhe me rastet me zëvendësim të valvulës aorte të izoluar. Diskutim tjetër është niveli i anastomozës proksimale e cila siç thamë më lart përcakton llojın e inreventit që do kryejmë. Në rastin e zëvendësimit të aortës dhe rrënjës së saj teknika e "Bentall i modifikuar" (me conduit te valvuluar) mbetet "Gold Standart". Kjo ishte procedura që realizuam edhe ne pasi rrënja e aortes dhe sinuset e Valsavës ishin shumë të dilatuar, dhe insuficiensa e valvulës së aortës ishte e përparuar.Në zëvendësimin e rrënjës dhe aortës ascendente, rezultate shumë të mira ka dhënë teknika e valvë-sparing "ruajtjes së valvulës" të aortës me implantim të ostiumeve koronare dhe zëvendësim të aortës ascendente, sipas Yacoub ose David. Por që preferohet në rastet elektive, me kuspise aortike intakte, pa dilatacion të rrënjës së aortës dhe me regurgitim aorte deri në të moderuar. Kjo teknike mbart riskun e reinterventit për insuficiensë të valvulës së aortës. Shkalla e dilatimit të rrënjës së aortës dhe insuficiensa e valvulës janë tregues të rëndësishëm për suksesin e interventit dhe rezultatin afatgjatë.

Lim et al. në studimin e tij me 120 raste ku u përdorën të dyja teknikat, Bentall dhe ajo sipas David, me një follow-up 5 vjecar. Nuk u evidentua ndryshim sinjifikative në mortilitet 88.4 $\pm 5.2 \%$ në grupin Bentall dhe $90.8 \pm 4.4 \%$ në grupin e "valve-sparing”. Madje, rezultoi një incidencë më e lartë e ri-ndërhyrjeve në rastet e "valve-sparing" si pasojë e rekurencës së insuficiencës severe aortale. 
A. Kaçani, A.Aliu, S.Kuçi, E.Mıle, A.Veseli, A Dibra, E Prifti

Autorët rekomandojnë kujdes në vendimmarrje në rastet me regurgitim sever të valvulës së aortës.

Përkundrazi Dias et al. raporton sinjifikativisht me shumë komplikime të lidhura me protezën mekanike në teknikën Bentall sesa në atë me ruajtje të valvulës aorte "David procedure" dhe me një diferencë në mortalitet në follow-up 7 vjecar.

Gjithsesi fillimi i përdorimit në teknikën Bentall të conduiteve të valvuluar me graft tubular Dacroni dhe valvul biologjike e ka minimizuar riskun e hemoragjisë në pacientët mbi 65 vjec.

\section{Konkluzioni}

Aneurizma gjigande aortës ascendente është një gjetje e rrallë, me prezantime klinike të ndryshme deri në asimptomatike. Trajtimi kirurgjikal mbetet trajtimi standart me rezultate shumë të mira. Përzgjedhja e teknikës operatore është shume individuale, në varësi të rastit dhe eksperiencës së kirurgut.

\section{Referenca}

1. European Journal of Cardio-Thoracic Surgery, Volume 46, Issue 4, October 2014, Pages 685-692

2. Sansone F, Actis Dato GM, Zingarelli E, Flocco R, Punta G, Forsennati PG, Parisi F, Bardi GL, del Ponte S, Casabona R. Giant Aneursym of the Ascending Aorta 37 Years after Aortic Valve Replacement. Arch Clin Exp Surg. 2012 X:X-X.

3. 7. Fiore A, Grande AM, Pellegrini C, Viganò M. A time bomb in the thorax: the giant ascending aortic aneurysm: case report. G Chir. 2012;33:24-25.

4. Clouse W.D., Hallett J.W., Jr., Schaff H.V., Gayari M.M., ]\[W3Q42 1 awqs1strup D.M., Melton L.J., III Improved prognosis of thoracic aortic aneurysms. JAMA. 1998;280:1926.

5. Agha R.A., Fowler A.J., Saeta A., Barai I., Rajmohan S., Orgill D.P. The SCARE statement: consensus-based surgical case report guidelines. Int. J. Surg. 2016;34:180-186.

6. Isselbacher E.M. 2005. Contemporary Reviews in Cardiovascular Medicine Thoracic and Abdominal Aortic Aneurysms; pp. 816-828. 
ANEURIZMA GJIGANDE E AORTËS ASCENDENTE TORAKALE

7. Cheung K., Boodhwani M., Chan K., Beauchesne L., Dick A., Coutinho T. Thoracic aortic

8. aneurysm growth: role of sex and aneurysm etiology. J. Am. Heart Assoc. 2017;6

9. Larson EW, Edwards WD: Risk factors for aortic dissection: Anecropsy study of 161 cases. Am J Cardiol 1984; 53:849.

10. Pressler V, McNamara JJ: Thoracic aortic aneurysm: Natural historyand treatment. $J$ Thorac Cardiovasc Surg 1980; 79:489

11. Pressler V,McNamara JJ: Aneurysm of the thoracic aorta: Reviewof 260 cases. $J$ Thorac Cardiovasc Surg 1985; 89:50.

12. Braunwald,Bonow,Mann,Zipes,Libby: Heart Desease, Deseases of Aorta 2012,13061949

13. Elefteriades JA,Farkas EA: Thoracic Aortic Aneurism. J Am Coll Cardiol $55: 841,2010$

14. Davies RR, Goldstein LJ, Coady MA, et al: Yearly rpture or dissection rate for thoracic aortic aneurysms. Simple prediction based on size. Ann. Thoracic surg 2002, $73: 1727$

15. Davies RR, Goldstein LJ, Coady MA, et alNovel mesaurements of relative aortic size predicts rupture of thoracic aortic aneurysms. Ann. Thoracic surg 2006, 81:169 